\title{
Hepatitis D Virus IgM Antibody Measurement
}

National Cancer Institute

\section{Source}

National Cancer Institute. Hepatitis D Virus IgM Antibody Measurement. NCI Thesaurus.

Code C119282.

The determination of the amount of hepatitis D virus IgM antibody in a biological specimen. 